\title{
TRANSPORT PROPERTIES OF N-PHENYLDITHIOLS SYSTEM ANCHORED ON CU[111] METALLIC CONTACTS
}

\author{
SETIANTO $^{\ddagger 1,2}$, TH. NIEHAUS ${ }^{2}$ \\ ${ }^{I}$ Department of Physics, Padjadjaran University Bandung, Indonesia \\ ${ }^{2}$ Institute of Theoretical Physics, University of Regensburg, Germany
}

\begin{abstract}
Abstrak. Molekul terkonjugasi adalah bahan yang banyak dikembangkan dan dipelajari untuk teknologi elektronik berbasis pada perangkat molekul tunggal. Dalam tulisan ini kami mengkaji dan mengamati sifat konduktansi berbagai molekul tunggal berdasarkan sistem cincin "n-fenil" yang dihubungkan dengan gugus thiol (Sulfur) pada kontak logam $\mathrm{Cu}$ [111]. Metode NonEquilibrium Green Function (NEGF) diimplementasikan dalam teori kerapatan fungsional (gDFTB) yang digunakan untuk menyelidiki sifat transportnya. Hasilnya menunjukkan bahwa, peningkatan cincin fenil akan mengurangi celah energi HOMO-LUMO. Namun, nilai konduktansi mengalami penurunan. Tingkat energi dari molekul (molekul terisolasi) melebar dan bergeser setelah disambungkan dengan kontak logam $\mathrm{Cu}$ [111].
\end{abstract}

Kata kunci : Molekul terkonjugasi, sifat transport, n-phenyldithiols

Abstract. Conjugated molecules are materials which are widely studied and developed for molecular electronic technologies focusing on single-molecule devices. In this paper we observed the molecular conductance of single molecule based on n-phenyl ring systems with linker thiol (Sulfur) anchored on $\mathrm{Cu}[111]$ contacts. The non-equilibrium Green's function (NEGF) implemented in density functional tight binding (gDFTB) is used to investigate the transport properties. Our result showed that, increase of the phenyl ring will decrease the HOMO-LUMO energy gap. However, the conductance is decrease. The energy level of the molecule (isolated molecule) broadens and shifts after anchoring to the $\mathrm{Cu}[111]$ contacts.

Keywords : Conjugated molecules, transport properties, n-phenyldithiols

\section{Introduction}

Development of electronic devices and technology especially in the field of single molecule electronic has been explored in many aspects. The most interested research topic is exploring electronic transport of materials which have conjugated systems such as phenyl, graphene, carbon nanotube, fullerene, etc. In the field of molecular electronic devices, fundamental concept of current flow at molecular level is important requirement to understand the transport of charge through a single molecule to the contact region. In particular, it depends on the interaction between molecule and metallic leads, orientation of the molecule [1], HOMO-LUMO energy gap of the device and length of the molecule. These complex mechanisms can be studied by using quantum mechanics. In context of molecular level and biological systems, quantum approach has been proven successfully as a scientific tool. [2].

In order to design the molecular electronic devices, we use conjugated molecules in the form of n-phenyl system to explore and understand their molecular conductance. It has been investigated by several scientists with various experiments [3, 8, 9, 11] and theoretically $[4,5,6,10,20]$. Molecular linking unit influences the tunneling efficiency

* email : setianto@phys.unpad.ac.id 
in metal-molecule-metal junctions using atomic force microscopy (CP-AFM) [7]. Although experimental techniques have obtained high accurate information on the surface process, detail investigation on the electronic structures by theoretical method based on density functional theory (DFT) is also important subject. Many theoretical studies based on DFT which related isolated system have been carried out. Some results have good agreement with the experimental data. These studies are success to predict properties of the complex system such as geometries [2, 12, 13, 14, 15]. In this paper, we investigate the electronic structures of all system using density functional tight binding (DFTB) with Slater-Köster parameter mio-01 [16], and Non-equilibrium Green's function (NEGF) has implemented to DFTB code (called gDFTB) [17] for transport calculation to obtain the electronic current of these models.

\section{Theoretical Model}

\subsection{Conjugated Molecules}

We have known hydrocarbon group such as benzene $\left(\mathrm{C}_{6} \mathrm{H}_{6}\right)$ and butadiene $\left(\mathrm{C}_{4} \mathrm{H}_{4}\right)$ were called conjugated compound. In these compounds each carbon atom has sp2 hybridization. All hybrids will form $\sigma$-bonds with neighboring atoms. The $2 \mathrm{pz}$ orbital is forming $\pi$-bonds with orbital $2 \mathrm{pz}$ from neighboring atoms. As shown in Fig. 1., $\pi$ bond is perpendicular to the plane of the molecule that has formed $\sigma$-bonds. $\pi$-electrons are not localized but rather easy to move along on the molecule. Because the $\pi$-bond lies on the plane which perpendicular with the molecule and the distance is large enough, the electron-electron interaction of $\pi$-electron and $\sigma$-electron are relatively small.[19].

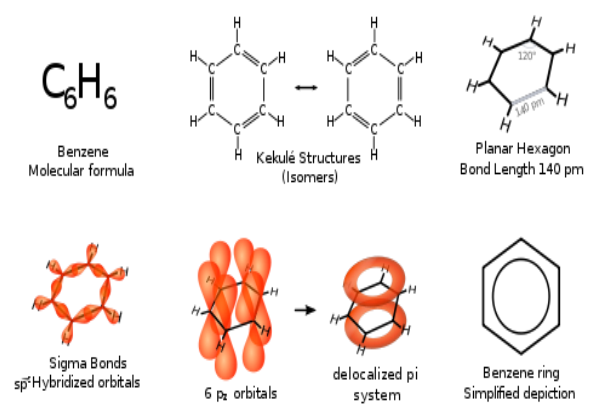

Figure 1. Benzene representation (picture from Wikipedia [18])

In molecular orbital theory, electrons are considered occupy in the molecular orbital which are widened to the entire of all nuclei in the molecule starting from lowest energy level following the Pauli principle. Because only valence electrons are involved in bonding, the atomic orbital is occupied by each valence electron to contributing a molecular orbital. Thus, a molecular orbital is seen as a linear combination of all atomic orbital's occupied by the valence electrons (linear combination of atomic orbital, LCAO). If the atomic orbital of $\mathrm{N}$ valence electron is $\varphi 1, \varphi 2, \varphi 3 \ldots \varphi \mathrm{N}$, so a molecular orbital can be constructed as:

$$
\psi=\sum_{j} c_{j} \varphi_{j} ; \quad j=1,2, \ldots \ldots \ldots, N
$$


where $c_{j}$ is the coefficient for the atomic orbital $\phi_{j}$ in molecular orbital $\psi$. These molecular orbital was first introduced by Roothaan [19].

In the ground state as shown Fig. 2, for $\mathrm{N}$ is even number then in accordance with Pauli principle that $1 / 2 \mathrm{~N}$ orbital is filled of electrons starting from the lowest energy level. This is called closed shell system. Orbital $\psi_{\mathrm{N} / 2}$ is the highest occupied molecular orbital (HOMO) and $\psi_{\mathrm{N} / 2+1}$ is the lowest unoccupied molecular orbital (LUMO).
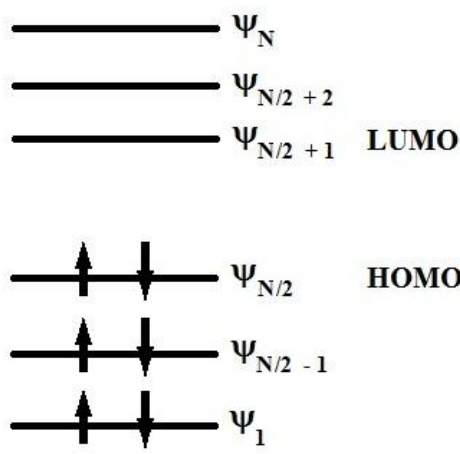

HOMO

Figure 2. The ground state of molecular orbital

In our study, we use n-phenyldithiol system as shown in Fig. 3 below:

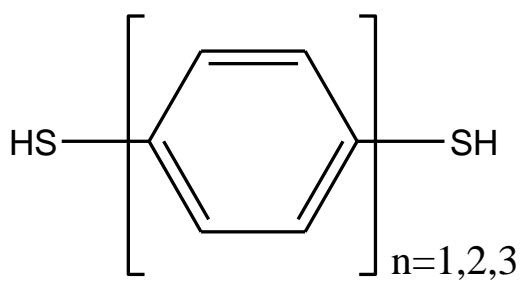

Figure 3. Conjugated molecules system: n-phenyldithiol system

The phenyl group or phenyl ring is functional group with formula $\mathrm{C}_{6} \mathrm{H}_{5}$ - where the six carbon atoms are arranged in a cyclic ring structure and often abbreviated as $\mathbf{- P h}$. A thiol is an organosulfur that contains a carbon-bonded (-C-SH or R-SH) group where $\mathrm{R}$ represents $-\mathrm{Ph}$ in this case.

\subsection{Molecular Conductance}

At molecular electronic devices, conductance of single molecule is a physical quantity which defined:

$$
G=I / V
$$

where $I$ is the current flow through to single molecule depends on applied bias $(V)$ from the metal contacts. There are many experiment techniques to measure this quantity directly [3, 8, 9, 11]. Most popular techniques are Mechanically Controllable Break Junction (MCBJ) experiment and Scanning Tunneling Microscope (STM) method. Toward to the goal of building the electronic devices at molecular level, the important 
step is the ability to measure and control the electrical current through single molecule. The current-voltage $(I-V)$ characteristic is very useful to understanding the electronic transport process and also to determine the molecular conductance of the device. Theoretically, the current can be described in context of the Landauer-Buttiker formalism [21] which relates the transmission probability $T(E, V)$ of an electron having energy $E$.

$I=\frac{2 e}{h} \int_{\mu_{1}}^{\mu_{2}} d E T(E, V)\left[f\left(E-\mu_{1}\right)-f\left(E-\mu_{2}\right)\right]$

where $\mu_{1}$ and $\mu_{2}$ are the electrochemical potentials in the two contacts which can be approximated by $\mu_{1}=E f-\eta e V$ and $\mu_{2}=E f+(1-\eta) e V$. Factor $\eta$ describes the electrostatic potential difference which is divided between two junctions. $T(E, V)$ calculated from molecular energy level and their coupling to a contact and $f(E)$ is the Fermi distribution function.

\section{Computational Methods}

The geometries for all molecules and surface are optimized by density functional tight binding (DFTB) [2]. The adsorption of all molecules on metal surface is optimized by ab-initio density functional theory (DFT-Siesta) which uses a conjugated gradient technique. In these cases, we used the PBE exchange-correlation functional form of the generalized gradient approximation (GGA) [22]. We implemented basis sets with diffuse functions scheme for the Copper surface with longer cutoff and slower decay than the bulk DZP orbital [23]. The $\mathrm{Cu}[111]$ has $(4 \times 4)$ surface unit cell and repeated geometry consisting six-layers. Our calculation includes necessary steps as follows: First of all is optimization the $\mathrm{Cu}$ [111] surface structure with k-point [4 4 1]. Next step is to get a stable structure of isolated molecules with SCC Tolerance $10^{-6}$ and Max Force Component $10^{-5}$. After that, we optimize the distance of molecules and $\mathrm{Cu}[111]$ contacts which is yield S-Cu bond length about $2.25 \AA$ and the $\mathrm{S}$ atom locate at hollow site.

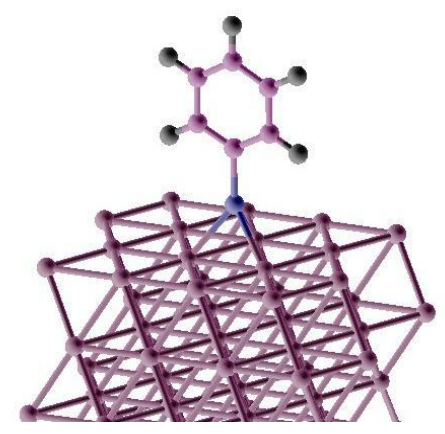

Figure 4. Benzene-thiol (BT) molecule adsorption on $\mathrm{Cu}[111]$ surface

Then we add other $\mathrm{Cu}[111]$ contact which serves as the source voltage (bias) to form molecular electronic devices with two terminal systems that is contact-moleculescontact as shown below: 


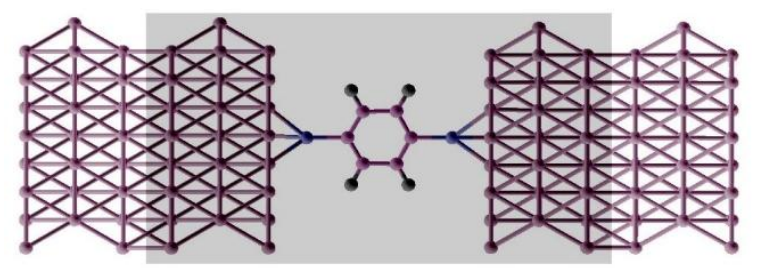

Figure 5. A Model molecular electronic device.

Finally, we apply Non equilibrium Green's function method to compute tunnelling current and I-V characteristics with gDFTB code [17] with parameter $\eta=0$.

\section{Results and Discussion}

\subsection{Geometry of molecules}

In Table 1 our calculated result of molecular parameters for n-PDT are obtained with DFTB. The interring distance is a C-C bond length between two phenyl rings. BiPDT and TriPDT have same length that is 1.474 Ångstrom. The twist angle is the torsion angle of two phenyl rings, $26.75^{\circ}$ and $26.58^{\circ}$ for BiPDT and TriPDT respectively

Table 1. Optimize geometry of all molecules All distance is in angstrom

\begin{tabular}{lccc}
\hline Molecule & $\begin{array}{c}\text { interring } \\
\text { distance }\end{array}$ & $\begin{array}{c}\text { twist } \\
\text { angle }(\theta)\end{array}$ & $\begin{array}{l}\text { molecule } \\
\text { length }\end{array}$ \\
\hline & & & \\
PDT & - & - & 6.258 \\
BiPDT & 1.474 & $26.75^{\circ}$ & 10.747 \\
TriPDT & 1.474 & $26.58^{\circ}$ & 15.041
\end{tabular}

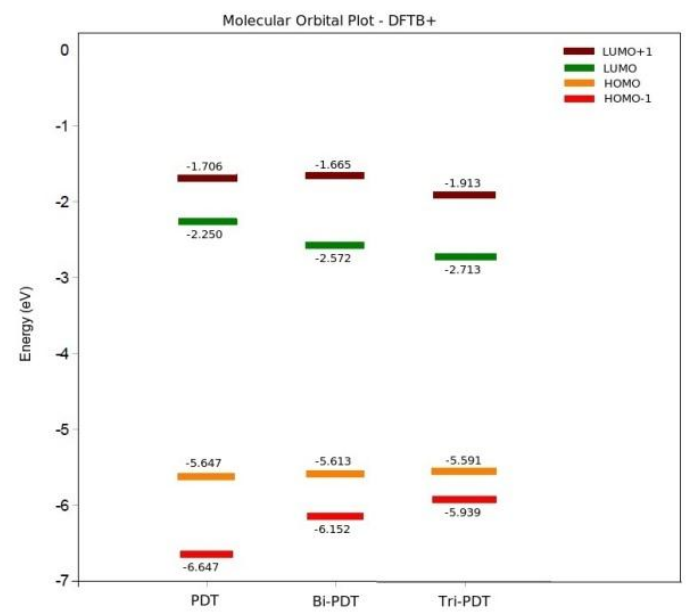

Figure 6. The HOMO and LUMO energy of isolated system. 
The frontier orbital of isolated molecules are plotted in Fig. 6. Increase of the phenyl ring will decrease the HOMO-LUMO energy gap. The values of energy gap are 3.3974 $\mathrm{eV}, 3.0405 \mathrm{eV}$ and $2.8783 \mathrm{eV}$ for PDT, BiPDT and TriPDT respectively and shown in Table 2.

Table 2. Energy gap of isolated system

\begin{tabular}{lc}
\hline & \\
Molecules & HOMO-LUMO gap (eV) \\
\hline & \\
PDT & 3.3974 \\
BiPDT & 3.0405 \\
TriPDT & 2.8783 \\
& \\
\hline
\end{tabular}

\subsection{Transport Properties}

In equilibrium, the energy level of the molecule (isolated molecule) broadens and shifts after anchoring to the $\mathrm{Cu}[111]$ contacts as shown in Fig. 7.

All HOMO and LUMO energy of molecules are shifted to the right (higher energy level) except the LUMO energy of PDT is shifted to the left. The Fermi energy of the $\mathrm{Cu}[111]$ for this calculation is $-3.725 \mathrm{eV}$. The broadening of the LDOS is related the strength of coupling to the contacts i.e. strong/weak hybridization with the delocalized metallic wave functions [24]. Afterward, the transfer electron charges from or to the molecule is possible. The transmission through the molecule has similar characteristic with the LDOS
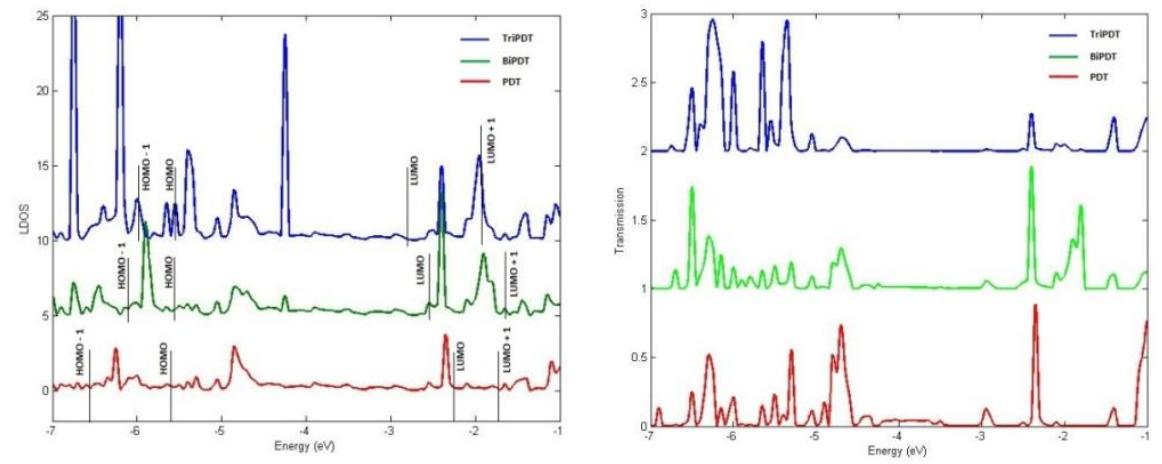

Figure 7. LDOS of n-PDT molecule versus energy (the HOMO and LUMO energy level of isolated system also shown) b. Transmission through the n-PDT molecule

In non-equilibrium, the I-V characteristics of molecules are shown in Fig. 8. At positive bias, PDT molecule almost has a linear current. The current characteristics of BiPDT and Tri PDT have nonlinear curve that looks similar shape. It can be explained as follows. From 0 to 1.5 volt, the current increase gradually, it means the chemical potential has difficulties to cross the molecular level. If the energy level is matched with the chemical potential, the current increase sharply as shown in the $I$ - $V$ curve from 1.5 to 2 volt. 

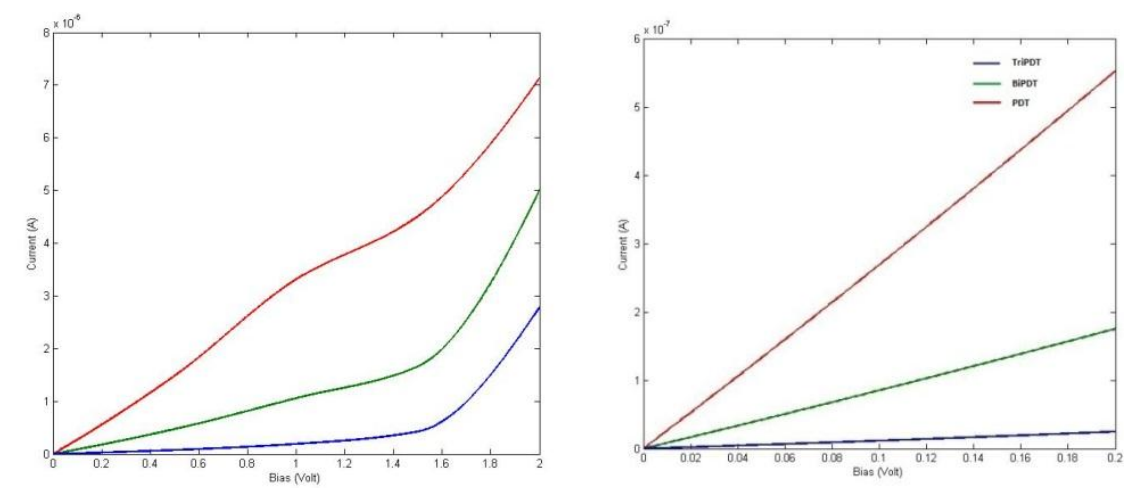

Figure 8. Current vs Voltage (I-V) of n-PDT a. positive bias voltage; b. low bias voltage

Table 3. Molecular Conductance

\begin{tabular}{lcc}
\hline & \multicolumn{2}{c}{ Conductance $\mathrm{G}(\mu \mathrm{S})$} \\
Molecules & Theory & Experiment \\
\hline & & \\
PDT & 2.634 & $0.833^{\mathrm{a}}$ \\
BiPDT & 0.834 & \\
TriPDT & 0.107 & \\
& & \\
\hline
\end{tabular}

${ }^{\mathrm{a}} \mathrm{BJ}$ experiment with $\mathrm{Au}$ contact[25]

The molecular conductance is given in Table 3. At low bias voltage ( 0 to 0.02 volt), all molecules have linear current. PDT has highest conductance that is $2.634 \mu \mathrm{S}$ due to the shortest molecule length is only $6.258 \AA$

\section{Conclusion}

Increasing the phenyl ring will be decrease the HOMO-LUMO energy gap. The potential profile can affect the I-V characteristic of molecular electronics device significantly. In gDFTB, it is obtained by solving the three dimensional Poisson equation.

\section{Acknowledgments}

We would like to thank A. Pecchia for short course of the gDFTB code. This work has been supported by the Ministry of National Education (Depdiknas) of the Republic of Indonesia.

\section{References}

1. T. S. Rufael, J. D. Batteas and C. M. Friend: Surf. Sci. 384 (1997) 156 -157.

2. Th. Frauenheim et al. Phys. Stat. Sol. (b) 217, 41 (2000).

3. M. Mayor, H. Weber, et al: Angew. Chem., Int. Ed. 42, 5834 (2003).

4. P. Rocheleau and M. Ernzehof : J. Chem. Phys. 130, 184704 (2009).

5. G. C. Solomon, D. Q. Andrews, et al: J. Chem. Phys. 129, 024901 (2008).

6. A. Pecchia, Th. Niehaus, et al: Physica E 19 (2003) 139 - 144. 
7. Alexei V. Tivanski, et al : J. Phys. Chem. B, Vol. 109, No. 12, 2005

8. Leif et al. : Science Vol. 323 (2009)

9. J. Repp et al. : NaturePhysics Lett. (2010)

10. Galperin et al. : Science 319, 1056-1060 (2008)

11. Venkataraman et al. : Nature Lett. Vol. 442, 904-907 (2006)

12. U. Schwingenschlögl, C. Schuster : Chem. Phys. Lett. 435 (2007) 100-103

13. W.T. Geng et al. : Thin Solid Films 464-465 (2004) 379-383

14. G. R. Hutchison et al.: Phys. Rev. B 68, 035204 (2003)

15. Zoppi et al.: Phys Rev B 78, 165204 (2008)

16. http://www.dftb.org/parameters/download/mio/mio_1_1/

17. A. Pecchia et al.: Physica E 19 (2003) 139-144

18. http://en.wikipedia.org/wiki/File:Benzene_Representations.svg

19. R. E. Siregar : Fisika Kuantum, Atom dan Molekul (2008)

20. Pauly et al. : Phys. Rev. B 77, 155312 (2008)

21. S. Datta, Electronic Transport in Mesoscopic System, Cambridge University Press, Cambridge, UK 1997

22. J. P. Perdew, K. Burke, and M. Ernzerhof, Phys. Rev. Lett. 77, 3865 (1996)

23. Garcia-Gil et al. Physical Review B. 79, 0754441 (2009)

24. Ferdows Zahid et al: Electrical Conduction through Molecules, Academic Press (2003)

25. Richard L. McCreery : Chem. Matter. 2004, 16, 4477-4496 